\title{
The Research on the Precision Funding Work of Higher Vocational Colleges under the Environment of Big Data
}

\author{
Yan Xiao-yan, SUN Shu, XUE Xiao-shuang \\ Taizhou Polytechnic College \\ Taizhou Jiangsu 225300
}

\begin{abstract}
Precision funding is an inevitable requirement for the development of university funding, and it is also the performance of the credibility of the country and school. The traditional funding identification work has some problems, such as insufficient coverage, difficult identification and poor educational effect. "Big data platform" and "smart campus" can effectively promote the precision identification and precision help of poor students and prevent online fraud. At the same time, a work-study platform is combined to promote students' support from blood transfusion to hematopoietic transformation, and enhance students' self-consciousness.
\end{abstract}

Keywords-Student funding; Big data platform; Higher vocational colleges; Work-study program

\section{INTRODUCTION}

The subsidization work of higher vocational colleges is an important support for the growth and cultivation of impoverished college students, and also the effective approach for realizing fair education and the important contents for the cultivation work of schools. 2016 Chinese Student Subsidization Development Report has put forward the conversion of students' subsidization development connotation from "security-type subsidization" towards "development-type subsidization", and it is requested to comprehensively promote "accurate subsidization", so it can be seen that the state has put forward new requirements for the strength and accuracy of subsidization work for poor students. The student subsidization management worker in higher vocational colleges must carefully think about how to improve the subsidization working mode for college students in "transformation period", improve the connotation and efficiency of subsidization work, and realize better subsidization effect.

\section{DILEMMA OF SUBSIDIZATION WORK DURING THE CURRENT PERIOD}

A. The subsidization range for students in higher vocational colleges is relatively insufficient and the strength is not enough

In the recent years, the quantity of students taking college entrance examination has been constantly decreased, while the enrollment scale of undergraduate colleges has been constantly expanded, which has seriously squeezed the source of students in higher vocational colleges. Taking Taizhou Polytechnic College (hereinafter referred to as the college) as an example, in order to maintain school-running scale, it is conscripted to largely increase the enrollment quantity of students in other provinces (especially the western area), and this has largely improved the proportion of poor students accordingly [1]. For instance, the proportion of student source in Gansu reached to above $70 \%$ considering the major of 2015 Grade Road Bridge Engineering Technology in the college, and the proportion of poor students was increased to about $70 \%$ from about $30 \%$ in previous years. But the proportion of national scholarship and grants in regular institutions of higher learning was merely $20 \%-25 \%$ of the quantity of students at school, and inevitably, partial poor students cannot enjoy the direct subsidization of national finance. Meanwhile, along with the increase of price level, the tuition and living expenses for students at school are also largely improved, and the living expenses of students was about RMB 1,000 per month, while the middle-level grant was merely RMB 3,000, so in case of merely relying on the state grants, it is impossible to thoroughly solve the life issues of students.

\section{B. Economic poverty identification is difficult}

The increase in the student source of other provinces has made the poor student identification work more difficult. Firstly, since students of other provinces are far away from here and are widely distributed, so the judgment basis is merely the personal statement of students and the poverty certificate from the origin of students, and it is impossible to conduct in-depth understanding about the family conditions through field interview, so the poverty identification is not fair enough. For instance, according to the report of freshmen in 
2015, Student Wen provided the local exceptional poverty certificate and the disability certificate of his mother to the college, but concealed the fact that his father was a project manager of a construction company, the college identified his to the grade of "particularly difficult" in family economic difficulties; although his qualification was canceled after the follow-up verification, negative influence was caused. Secondly, partial personnel of civil administration organs, teachers and student cadres would use their personal standard to disturb and influence the identification work of poor students. These factors will cause the phenomenon of "subsidizing those who don't need the assistance, rather than the needy" in subsidization work, and will not only waste the state fund, but also make the school and state lose credibility.

The subsidization identification process lacks in standard. Currently, the existing subsidization management method for poor students in our country doesn't have relatively sound and scientific identification standard. The subsidization basis of colleges for students is mainly reflected in family background investigation (whether there is single parent, several children, disability, etc.) to qualitatively describe and confirm poor students, and cannot provide a quantitative judgment standard, so there can always be obvious subjectivity in the identification process. On the other hand, since the origins of students are different, the economic level development conditions have obvious differences; besides, there can also be certain difference in the basic cost of living allowances. Thus, it lacks in certain scientificity and systematicness in the identification standard of poor students, and this has made it hard to avoid the occurrence of deviation in the identification result of poor students.

\section{Emphasis on material subsidization and less emphasis on spiritual support}

The subsidization work of the state for poor students is always helping students complete their studies and in life from economic layer, but in the subsidization working process, we find that most poor students have self-abasement, sensitivity, anxiety, depression and other psychological problems. Some students will give up the application of subsidization fund because of their worries about the exposure of family conditions; some of them even generate a strong vanity, and spend lots of money to prevent other students from looking down upon them; some students may be isolated by other students due to self-enclosure, and social phobia. Therefore, the assistance work for poor students shouldn't consider economic aspects only, the spiritual assistance is more important, to help them release spiritual pressure, overcome inferiority complex, establish confidence and then perfect themselves, and blend themselves in class, and keep a foothold in the society.

Meanwhile, the student aid mode of unpaid subsidization will make students generate sluggishness and anaclisis, and don't have gratitude, lack in the spirit of self-improvement and the upward mobility of self-accomplishment.

\section{III. "Big DATA PlATFORM" IS AN IMPORTANT MEANS FOR ACCURATE SUBSIDIZATION}

The big data platform can conduct data collection through radio frequency identification, sensor, network classification search engine and other modes, and through appropriate analysis algorithm, filter out false, deviation and abnormal data, effectively avoid the disturbance of manual subject factors, objectively and accurately analyze data, truly reflect the essence of things, and accurately identify students with economic difficulty in each family and the difficulty degree.

Accurate identification is the basis and precondition for student subsidization, and it requests the student identification materials to be true and reliable; the identification standard and subsidization grade should be scientific and normalized, and the identification procedures should be reasonable and accurate. As per the national guidance standard, collect and analyze the economic conditions of the family where the individual student locates, the employment conditions, major disease conditions and local minimum life guarantee line, the local minimum life guarantee line for urban residents in the city where the college locates, the basic study and living expenses guarantee line for students in the city where the college locates, the college subsidization fund quota, charging level and other basic data, select and calculate the core variable and index weight for judging the economic difficulty degree of the family, and construct the quantitative index system for family economic difficulty identification and subsidization grade division.

Big data platform can conduct archive type management for students, and comprehensively cover the daily life and learning conditions of students. Implement dynamic monitoring on the campus card consumption, network shopping and other data of freshmen after the entrance, and find out non-assistant students who are subject to poverty due to various accidents and "false poor students" who conceal the report or falsely report in the first time, adjust subsidization object in real time and ensure "the support of true poor students". Effectively avoid the randomness, subjectivity and experience in poverty certificate method and comprehensive evaluation and judgment method as well as the false subsidization judgment and wrong subsidy configuration incurred thereby.

Along with the popularization of internet and smart phones, internet has given fraud crimes a lift, and this has become increasingly furious. Criminals can use high-tech tools, network number changing mode and other advanced technologies to forge false information, set up fraud, and implement telecommunication fraud for the victim through phone calls, SMS and network mode, and bring a huge influence to the life and property of the victim. However, due to the lack of social experience, weak anti-risk capacity, once being encountered with online fraud loss, unpredicted consequences will be often generated to the poor students. This requests the interception of telecommunication fraud through big data and internet+ technology. For dangerous telecommunication numbers, there should be prompt before answering it, and huge amount of account entry and expenditure can only be operated with the secondary 
confirmation of the class teacher or counselor and other modes, so as to effectively decrease the possibility for poor students to encounter with online fraud. Meanwhile, it is also requested to intercept and alert similar websites like "campus loan" on the internet, and meanwhile, combine the daily observation of students as well as the periodic analysis about the relevant account data of students, timely find out students who have economic difficulties go off the track, and prevent them from being caught up in "campus loan" and pyramid selling trap.

Under the support of big data technology, schools can combine the actual conditions and the demand of students and then design the subsidization project that is urgently requested and easily accepted by students. For instance, during the entrance, it is applicable to set "the deferred payment of tuition + student loan", "interest-free loan + living subsidy" and other subsidization projects to help students complete normal entrance work, without letting any student drop out of school because of the tuition problems; during the academic year, provide "work-study posts + scholarship + tuition waiver + social security payment on behalf" and other forms of subsidization; students with major domestic calamity can also enjoy "beneficent funds + one-time difficulty subsidization" policy; and meanwhile, discuss with the internship employer, and ask them to provide staff dormitory and food allowance for poor students. Diversified subsidization modes can remove obstacles for students to successfully finish their studies.

Through big data platform and work-study program platform in combination with the professional background, interests, hobbies and character traits of students, etc., deeply dig out the work-study posts on campus, and provide suitable work-study posts for each registered poor student, fully develop the "hematopoietic" function of work-study program, which can not only alleviate the state burden, but also improve the living level of poor students, and improve the innovation and entrepreneurship capacity of students, make them better go towards the society, and adapt to the future working environment. The work-study posts are not constrained by restaurant servers, salesmen, cleaners, librarians and other work with low technical contents, but also more related to the specialty and hobbies of students, for instance, the teaching assistant for teachers, class assistant, scientific research assistant and other posts; the secretary for the administrative department of the school; the laboratory manager and political instructor. Work-study posts with high technical contents can not only solve the economic problems of poor students, but also let students learn more professional knowledge and skills through work, and obtain bigger satisfaction in spirit. When being compared with unpaid subsidization, the remuneration obtained by students through their own work can change their life, and make them more easily believe that they can change their own fate through making endeavors.

For instance, Student Ni who was majoring in 2013 Grade construction Decoration Engineering Technology in Taizhou Polytechnic College joined in the design team of Teacher Cao majoring in decoration during the first term of college life, from the most basic house measurement, the middle-term construction drawing design to the follow-up effect picture design, she has learned progressively, and slowly stepped in the right direction. During her learning period, she completed many projects, and had not only obtained rich remuneration, but also learned working skills and working experience. It didn't cause any influence to her daily academic performance, but had strengthened her learning effect, applied theories into practice, and further consolidated theories through practice; her performance ranked top in the class. More importantly, within two years after graduation, when other students just completed the conversion process from workplace newbie to technical backbones, she has converted to an independent designer (entrepreneurship) from the technical backbone of designing institute.

As the contact bond between students and employers, the work-study program platform should realize the following aspects. Firstly, it should fully dig out the quantity and form of work-study program posts, and provide diversified posts for students[4]; secondly, it is requested to analyze the class performance, academic performance, book borrowing, public activity participation as well as Microblog, WeChat, net comments and other behavior data of students with economic difficulty, and prepare qualified candidates for the post; secondly, it is requested to utilize mutual evaluation system for mutual evaluation, restrain the two parties, and ensure the legal interests of the two parties; the platform should also collect post skills, provide post training for students, and help students adapt to post demand as soon as possible.

\section{Big DATA SUBSIDIZATION PlatForm GUARANTEE SYSTEM}

The big data subsidization platform can help schools accurately identify students with financial difficulties through big data, and decrease the possibility for students to give up accepting the aid due to worries about the exposure of their privacy; besides, this can also prevent students from "campus loan", network pyramid sales, online fraud and other vicious incidents; it can also provide individual service for poor students, etc. however, since this platform includes lots of personal information about students, if it fails to attract attentions or fails to be protected, the consequences will be disastrous. Thus, it cannot be ignored to establish sound big data security guarantee mechanism.

System guarantee; the subsidization management platform driven by big data can involve the collection, storage, disposal and application of personal information about lots of poor students and non-poor students. Once fault occurs, unpredictable consequence will be generated, thus, it is necessary to establish information data using standardizing system, and safety protection system.

Personnel guarantee; in the process of using big data to manage poor students, the working personnel should correctly interpret data, fully understand identification work procedures, and sufficiently communicate with relevant other functional departments. Such work requests the working personnel to possess information technology, subsidization management experience, psychological counseling and other capacities. Thus, long-term valid cultivation mechanism should be established for the subsidization management personnel.

Technology and fund guarantee; since the big data platform involves multi-terminal, multi-user, big operation 
and other technologies, so it is a complicated and comprehensive information system. Thus, it is requested that there should be a professional technical team to provide longterm service, and ensure its safe and valid operation. The construction of big data platform will certainly request certain software and hardware investment and manpower cost, and all of these are the key of operation. Without sufficient fund and enough technology, the big data platform cannot be normally used.

\section{SUMMARY}

The implementation of accurate subsidization is very meaningful to educational poverty alleviation, and in order to reach the objective, the key is to obtain accurate information about the subsidized students, and the big data platform is an important approach for obtaining accurate information; meanwhile, it is requested to input lots of manpower and resources to ensure stable and correct operation, so as to help poverty students to successfully complete school work, and play an important role in their growth and cultivation.

\section{ACKNOWLEDGMENT}

About the Author: Yan Xiaoyan (1983- ), female, born in Taizhou of Jiangsu, the Lecturer and Master of Taizhou Polytechnic College, and the research direction is students education management.

E-mail: 77642753@qq.com

Fund Project: 2018 Jiangsu Colleges Philosophy and Social Science Research Fund "Research about Practical
Cultivation of Work-study program in Higher Vocational College Based on the Background of Innovation and Entrepreneurship"; 2018 Vocational Education Research Fund "The Study of Practical Education in Higher Vocational Colleges"; 2017 Taizhou Polytechnic College Topics "Research about the Construction and Operation Mechanism of College One-stop College Students Service Center", No. TZYKY-17-17.

\section{REFERENCES}

[1] Wu Pingliang. Problems and Countermeasures for the Subsidization Policy System of poor students in Higher Vocational Colleges [J]. Electronic Production, 2013, 23:255.

[2] Yuan Wenhua and Yue Dan. Investigation and Analysis about the Basic Conditions of poor students in Colleges_-Taking Anhui University of Science and Technology as an Example [J].Journal of Suzhou University, 2007, 04: 125-127.

[3] Ma Yanzhou and Gao Fuyang. Research about the Necessity for Colleges to Construct Developmental Subsidization [J]. Hubei Social Sciences, 2011, 01: 180-182.

[4] Liang Guangdong, Zhao Shuang, Sheng Shuying, and Feng Pengyu. Research about the Construction of Accurate Subsidization System for College Students under New Normal [J]. Journal of Henan Institute of Science and Technology, 2017, 3702: 29-31.

[5] Huang Shaoling. Discussion about the Construction of "Poverty Aiding" and "Talent Cultivation" Combined Subsidization System for College Students [J]. School Party Construction and Ideological Education, 2009, 23: 63-65.

[6] Huang Yan and Wang Linqing. Discussion about the Scientific Construction of Identification Mechanism for College Students with Economic Difficulties [J]. Heilongjiang Researches on Higher Education, 2010, 05: 122-124. 